\title{
5th International Conference On
}

Modern Approaches in SCIENCE,

TECHNOLOGY \& ENGINEERING

29 - 31 August, 2019

Germany, Berlin

\section{The Flame Retardancy of Charring Agent MTHEIC on Flame Retarded Polypropylene Composites}

\author{
Shang Gao', Huimin Zou², Gousheng Liu ${ }^{3}$ \\ College of Chemistry, Nanchang University, Nanchang 330031, China
}

\begin{abstract}
Charring agent MTHEIC was synthesized by using maleic anhydride (MAH) and tris(2hydroxyethyl) isocyanurate (THEIC) as raw materials, its chemical structure was characterized by fourier transform infrared (FTIR) spectra, ${ }^{1} \mathrm{H}-\mathrm{NMR}$ spectra and elemental analysis. The synergistic effects between MTHEIC and ammonium polyphosphate (APP) on flame retarded polypropylene (PP) were investigated. Results illustrated that when mass ratio of APP/MTHEIC 2:1 with $30 \mathrm{wt} \%$ IFR loading, PP/IFR composites could reach LOI $35.2 \%$ and pass UL-94 V-0 rating. Results from SEM, TGA and FTIR indicated that a continuous and intumescent char layer was formed during combustion. Cone colorimeter results indicated that the IFR could reduce pHRR and THR by $70.6 \%$ and $22.0 \%$, respectively, compared to neat PP. The PP/IFR composites passed UL-94 V-0 rating after soaking in $70^{\circ} \mathrm{C}$ water for $120 \mathrm{~h}$ when IFR was $30 \mathrm{wt} \%$ with mass ratio APP/MTHEIC 2:1, and UL-94 V-1 rating could be reached after 144 hrs. Tensile strength and flexural strength of PP/IFR composites decreased by $28.1 \%$ and $19.5 \%$, respectively, compared with neat PP.
\end{abstract}

Key words: THEIC-based charring agent; Maleic anhydride; intumescent flame retardant; Water resistance. 


\section{Introduction}

Intumescent flame retardant (IFR) has good application as a safe and friendly flame retardant to polymeric materials. The proposed mechanism is the carbonaceous foam acting as a physical barrier, slowing down heat and mass transfer between the gas and the condensed phase $^{1,2}$. A traditional IFRs system ${ }^{3}$ is the combination of ammonium polyphosphate (APP), pentaerythritol (PER) and melamine (MEL) (APP/PER/MEL). However, this formula have poor compatibility with polyolefins and are easy to migration ${ }^{4}$, the surface of polyolefins is somewhat like 'sweating' or 'sticky' when polymeric materials expose in hot and humid place for a period of time. This is because the charring agent PER in APP/PER/MEL system is a small molecular compound, it is moisture sensitive and easily attacked by water and exuded out of the mixture, leading to a severe deterioration of flame retardancy.

One solution to this problem is selection of macromolecular charring agent. Triazines and their derivatives have been attracted great attention owing to the stable triazine rings, little water solubility and char forming easily during combustion ${ }^{5-11}$. Moreover, these agents have superior charring effect because

they contain abundant nitrogen and possess a structure of tertiary nitrogen. $\mathrm{Hu}^{12}$ synthesized a triazine derivative as a charring agent to use with APP for flame retardancy of low-density polyethylene (LDPE). $\mathrm{Nie}^{13}$ synthesized a macromolecular triazine derivative CFA, the synergistic effects between CFA and microencapsulated APP on thermal and flame retardancy of PP were investigated. Wen ${ }^{14}$ synthesized a triazine charring agent HCFA, which possessed high thermal stability, excellent char forming capability

and good water resistance, the PP/IFR composites with thickness $1.6 \mathrm{~mm}$ passed UL-94 V-0 rating after soaking in hot water for $168 \mathrm{~h}$ when IFR was $30 \mathrm{wt} \%$ with mass ratio APP/HCFA from 3:1 to 1:1.

However, the synthesis process of triazine-based charring agents generally uses cyanuric chloride as raw material in organic solvent. For example, charring agent N-methyl triazineethylenediamine copolymer ${ }^{5}$ was synthesized from cyanuric chloride, methylamine and ethylenediamine through nucleophilic reaction in acetone solvent; The charring agent HPCA ${ }^{11}$ was synthesized from cyanuric chloride, 4,4'-diaminodiphenyl sulfide and diisopropyl ethylamine in N-methyl-2-pyrrolidone (NMP) solvent.

As we know, cyanuric chloride is a colorless crystals with pungent odor, this substance is severely irritating to the eyes, skin and respiratory tract, it can react with water and produce cyanuric acid, hydrochloric acid and heat, its UN hazard class is 8 . On the one hand, cyanuric 


\section{5th International Conference On}

Modern Approaches in SCIENCE,

TECHNOLOGY \& ENGINEERING

\section{9 - 31 August, 2019 \\ Germany, Berlin}

chloride is harmful to operators; On the other hand, solvents such as acetone and NMP are used in this process, though solvents are recycled, trace solvent residues in charring agent may lead to safety and health uncertainty, especially in food packing, medical and biomedical plastic materials. The national standard GB/T10004-2008 "Packaging plastic composite membrane, bag dry composite, extrusion compound" ${ }^{15}$ stipulates that total solvent residues in food packing plastic materials should be less than $5 \mathrm{mg} / \mathrm{m}^{2}$, and benzene-containing solvents should be less than $0.01 \mathrm{mg} / \mathrm{m}^{2}$. According to European Commission regulation ${ }^{16} 1935 / 2004$, substances migrating into food should not be harmful to humans, benzene derivatives are strictly prohibited in foodstuffs.

In recent years, our group has prepared a series charring agents based on tris (2hydroxyethyl) isocyanurate (THEIC), all the synthesis processes are one-pot melt copolymerization, no organic solvents are used, no harmful subjects are released except water. Thus, THEIC-based charring agents should supply more safety and more convenient user experience for food packing, medical and biomedical plastic materials. The flame retardant properties, thermal stability and burning behavior for flame retarded polypropylene or polylactide are steadily investigated, including:

(1) tetramer (TT4) using THEIC and terephthalic acid as raw materials. ${ }^{17,18}$

(2) tetramer (TT4) and dimer/trimer mixture (TT23). ${ }^{19}$

(3) microencapsulation of APP with melamine-formaldehyde-THEIC resin. ${ }^{20}$

(4) the self-etherification of THEIC molecules (homo-THEIC). ${ }^{21}$

(5) an integrated IFR (TPM) by THEIC, polyphosphoric acid and melamine as raw materials. $^{22,23}$

In this paper, another THEIC-based charring agent MTHEIC was synthesized by reaction of maleic anhydride (MAH) and THEIC through one-pot melt polymerization process, the synergistic effect between MTHEIC and APP on flame retardancy of polypropylene was studied, water resistance and mechanical properties of PP/IFR composites were also studied.

\section{Experimental}

\subsection{Materials.}

PP resin (T30s, melt-flow rate $2.3 \mathrm{~g} / 10 \mathrm{~min}$ ) was supplied by SINOPEC Maoming Company, China. APP (n>1000) was supplied by Shandong Shi'an Chemical Company, Co., Ltd.

THEIC was supplied by Changzhou Lantian Chemical Company, Co., Ltd. MAH was supplied by Zaozhuang Chemical Co., Ltd. The synthesis route of charring agent MTHEIC is shown in scheme 1. 


\section{5th International Conference On}

Modern Approaches in SCIENCE,

TECHNOLOGY \& ENGINEERING<smiles></smiles><smiles>O=C(/C=C/C(=O)OCn1c(=O)n(CO)c(=O)n(CO)c1=O)OCCn1c(=O)n(CO)c(=O)n(CO)c1=O</smiles>

Scheme1 Synthetic route of MTHEIC

\subsection{Synthesis of MTHEIC.}

$261 \mathrm{~g}$ THEIC and $49 \mathrm{~g}$ MAH were mixed and heated to $150^{\circ} \mathrm{C}$ in a $500 \mathrm{~mL}$ four-necked flask equipped with a stirrer, $2.2 \mathrm{~g}$ 4-methylbenzenesulfonic acid as catalyst was added, the mixture was heated to $190^{\circ} \mathrm{C}$ and reacted for $8 \mathrm{hrs}$, the condensed water was continuously removed. When there was no water released, the reaction was stopped. The mixture was cooled to room temperature and crushed to white powder.

\subsection{Preparation of PP/IFR composites}

All samples were prepared in a pressurized kneader at $180{ }^{\circ} \mathrm{C}$, the screw speed was kept at $20 \mathrm{rpm}$. Neat PP was put in the pressurized kneader, after neat PP was melt, APP and MTHEIC were added, and mixed for $10 \mathrm{~min}$. PP/APP/MTHEIC composites were hot-pressed under $14 \mathrm{MPa}$ at $180^{\circ} \mathrm{C}$ for $10 \mathrm{~min}$ to make suitable specimens. The formula of all samples are listed in table 1.

Table 1 Flame retardancy of PP/IFR composites

\begin{tabular}{ccccccc}
\hline Samples & PP $(\mathrm{wt} \%)$ & APP $(\mathrm{wt} \%)$ & MTHEIC(wt\%) & APP/MTHEIC & LOI $(\%)$ & UL-94 \\
\hline PP0 & 100 & 0 & 0 & $/$ & 17.5 & No rating \\
PP1 & 70 & 30 & 0 & $/$ & 20.0 & No rating \\
PP2 & 70 & 27 & 3 & $9: 1$ & 32.5 & V-0 \\
PP3 & 70 & 25 & 5 & $5: 1$ & 34.3 & V-0 \\
PP4 & 70 & 22.5 & 7.5 & $3: 1$ & 34.5 & V-0 \\
PP5 & 70 & 20 & 10 & $2: 1$ & 35.2 & V-0 \\
PP6 & 70 & 15 & 15 & $1: 1$ & 34.2 & V-0 \\
PP7 & 70 & 10 & 20 & $1: 2$ & 30.0 & V-0 \\
PP8 & 75 & 16.67 & 8.33 & $2: 1$ & 32.0 & V-0 \\
PP9 & 70 & 0 & 30 & $/$ & 22.4 & No rating \\
\hline
\end{tabular}




\section{5th International Conference On}

Modern Approaches in SCIENCE,

TECHNOLOGY \& ENGINEERING

\section{9 - 31 August, 2019 \\ Germany, Berlin}

Fourier transform infrared (FTIR) spectrum was recorded on a Bruker-Vertex 70 FTIR spectrometer, scan range is $400 \sim 4000 \mathrm{~cm}^{-1}$ and samples were prepared with $\mathrm{KBr}$ pellets. ${ }^{1} \mathrm{H}$ NMR spectra were conducted at $400 \mathrm{MHz}$ on an AVANCE 500 spectrometer, using trichloromethane $\left(\mathrm{CHCl}_{3}\right)$ as solvent.Limiting oxygen index (LOI) values were measured on a JF-3 instrument (Jiangning, China) with sample dimension of $100 \times 6.5 \times 3 \mathrm{~mm}$ according to ASTM D2863-97.Vertical burning tests (UL-94) were tested on a CZF-2 instrument (Jiangning, China) with sheet dimension of $130 \times 13 \times 3 \mathrm{~mm}$ according to ASTM D3801.Thermogravimetric analysis (TGA) was carried out on Diamond TG/DTA (PE, America) thermal gravimetric analyzer. Heating rate is $10{ }^{\circ} \mathrm{C} / \mathrm{min}$ from room temperature to $800{ }^{\circ} \mathrm{C}$ using air flow and flowing rate is $20 \mathrm{~mL} / \mathrm{min}$. Cone colorimeter test was performed on Stanton Redcroft cone calorimeter and heat flux is kept at $50 \mathrm{Kw} / \mathrm{m}^{2}$. The sample dimension is $100 \times 100 \times 3 \mathrm{~mm}$ according to ISO-5660.The surface morphology of char residue after LOI test was observed by scanning electron microscopy (JSM-6360LV, Japan) with accelerating voltage $15 \mathrm{kV}$. Water resistance of PP/IFR composites: the specimens were soaked in distilled water at $70^{\circ} \mathrm{C}$ and were kept at this temperature for various time period. The specimens were subsequently taken out, dried in vacuum oven, and evaluated by LOI and UL-94 tests. Tensile strength and flexural strength of PP/IFR composites were tested using a universal testing machine (QJ212, Shanghai Qunji instruments Co. Ltd.). Tensile strength was tested by GB/T 1040-92 with stretch rate $10 \mathrm{~mm} / \mathrm{min}$; flexural strength was tested by GB/T 9341-2000 with test sample $80 \times 10 \times 4 \mathrm{~mm}^{3}$ and with compression rate $5 \mathrm{~mm} / \mathrm{min}$.

\section{Results and Discussion}

\subsection{Characterization of MTHEIC}

FTIR spectrum of MTHEIC is shown in figure 1. The absorption at $3460 \mathrm{~cm}^{-1}$ is assigned to the vibration of $-\mathrm{OH}$. The absorption peaks at 2968 and $2890 \mathrm{~cm}^{-1}$ are assigned to the asymmetric and symmetry stretching vibration of $-\mathrm{CH}_{2}$. The peak at $1465 \mathrm{~cm}^{-1}$ is assigned to deformation vibration of $-\mathrm{CH}_{2}$. The areas of 1680 and $1050 \mathrm{~cm}^{-1}$ are assigned to the vibration of $\mathrm{C}=\mathrm{O}$ and $\mathrm{C}-\mathrm{O}$, respectively. Furthermore, the absorption peak at $1167 \mathrm{~cm}^{-1}$ is assigned to the vibration of C-O-C. The appearance of C-O-C is the evidence of the reaction between MAH and THEIC. 


\section{5th International Conference On}

Modern Approaches in SCIENCE,

TECHNOLOGY \& ENGINEERING

29 - 31 August, 2019

Germany, Berlin

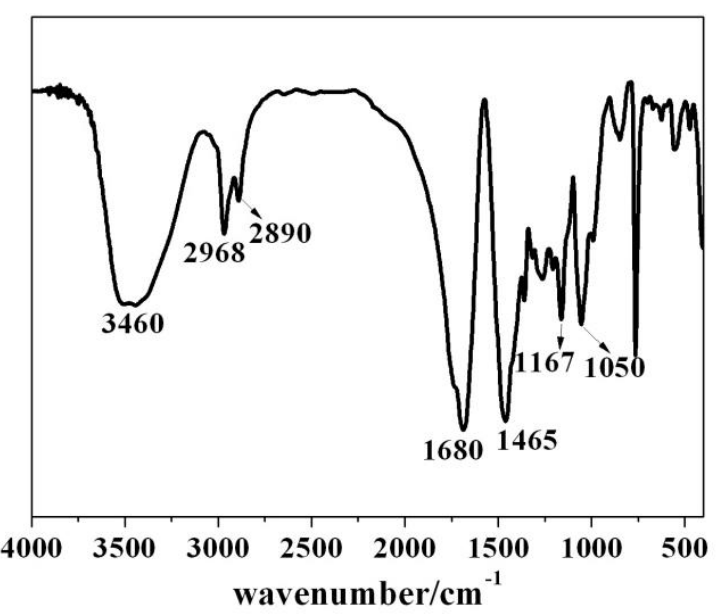

Fig.1 FTIR spectrum of MTHEIC Fig.2

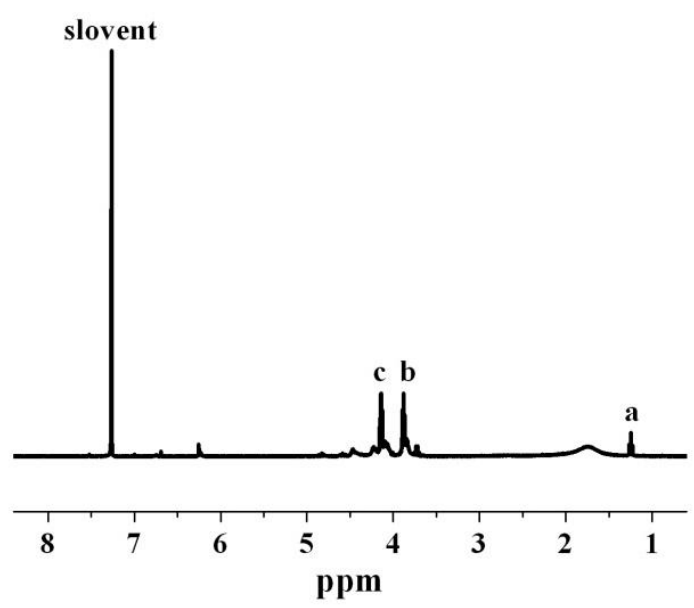

1H-NMR spectrum of MTHEIC

${ }^{1} \mathrm{H}$ NMR spectrum of MTHEIC is shown in figure 2 . The peak at $\delta=1.23$ is assigned to hydrogen of the unreacted $-\mathrm{OH}$ in THEIC. The range of $\delta=3.71 \sim 4.30$ is assigned to hydrogen in $-\mathrm{CH}_{2}-\mathrm{CH}_{2}$, but this peak is broken into multi-peaks due to complex chemical environment.

Results of elemental analysis are shown in table 2. The experimental contents of $\mathrm{C}, \mathrm{H}$ and $\mathrm{O}$ are consistent with those of calculation.

Table 2 Elemental and calculation of the synthesized MTHEIC

\begin{tabular}{cccccccc}
\hline \multirow{2}{*}{ Sample } & \multicolumn{3}{c}{ Calculated (\%) } & & \multicolumn{3}{c}{ Experimental (\%) } \\
\cline { 2 - 4 } \cline { 6 - 7 } & $\mathrm{C}$ & $\mathrm{N}$ & $\mathrm{H}$ & & $\mathrm{C}$ & $\mathrm{N}$ & $\mathrm{H}$ \\
\hline MTHEIC & 43.85 & 13.95 & 4.98 & & 43.24 & 13.55 & 4.98 \\
\hline
\end{tabular}

\subsection{Flame retardancy of PP/IFR composites}

UL-94 and LOI results are shown in table 1.

From table 1, LOI value of PP0 is only $17.5 \%$. When $30 \mathrm{wt} \%$ APP or MTHEIC was added to PP, LOI values of PP/APP and PP/MTHEIC are $20.0 \%$ and $22.4 \%$, respectively, both of them cannot pass UL-94 V-0 rating. This indicates that single APP or MTHEIC cannot improve the flame reatardancy of PP. However, LOI values increase remarkably when APP and MTHEIC are added together. When IFR loading is $30 \mathrm{wt} \%, \mathrm{PP} / \mathrm{IFR}$ composites (PP2-PP7) pass UL-94 V-0 rating and their LOI values are higher than $30.0 \%$, of them, PP5 has the highest LOI value of $35.2 \%$. This indicates that mass ratio of APP/MTHEIC 2:1 is the best. Furthermore, when IFR loading reduces to $25 \mathrm{wt} \%$ with mass ratio APP/MTHEIC 2:1, PP8 can also pass UL-94 V-0 rating. 


\section{5th International Conference On \\ Modern Approaches in SCIENCE, \\ TECHNOLOGY \& ENGINEERING}

29 - 31 August, 2019

Germany, Berlin

\subsection{Thermal stability analysis}

The degradation curves of PP0, PP2, PP5 and PP7 are shown in figure 3, relevant data are listed in table 3. From figure 3 and table 3, PP0 decomposes in one step from $257^{\circ} \mathrm{C}$ to 330 ${ }^{\circ} \mathrm{C}$, there is no char residue at $400{ }^{\circ} \mathrm{C}$. When $30 \mathrm{wt} \%$ IFR is added, char residues of PP/IFR composites increase remarkably. PP2 has the highest char residue and PP7 has the lowest when temperature is lower than $600{ }^{\circ} \mathrm{C}$. However, char residues of PP2, PP5 and PP7 at 700 ${ }^{\circ} \mathrm{C}$ are $1.63 \%, 2.81 \%$ and 2.13 , respectively.

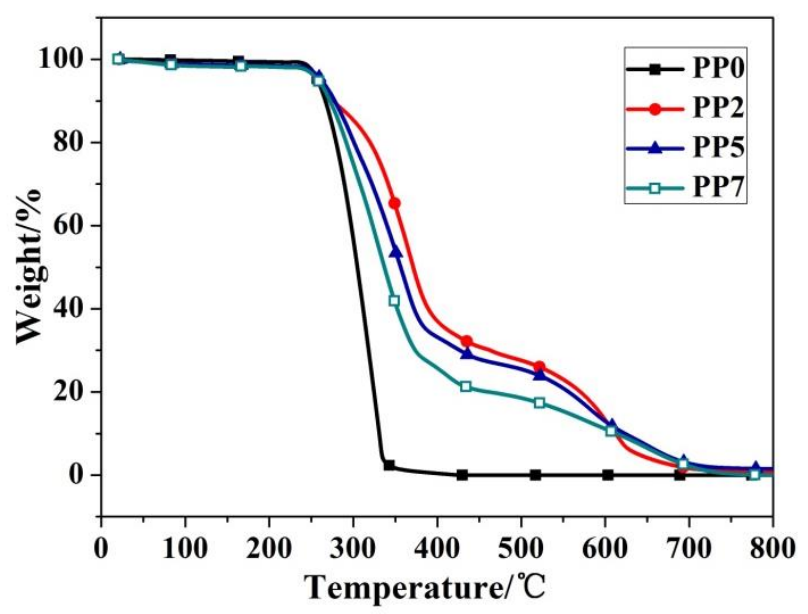

Fig.3. TG curves of PP0, PP2, PP5 and PP7

Table 3 TG of PP0, PP2, PP5 and PP7 in air

\begin{tabular}{cccccccc}
\hline Samples & $\mathrm{T}_{\text {onset }}$ & $\mathrm{T}_{\max }$ & Rate of $\mathrm{T}_{\max }$ & & \multicolumn{3}{c}{ Char residues $/ \%$} \\
\cline { 2 - 4 } \cline { 7 - 8 } & $\square$ & $\square$ & $\% / \min$ & & $500 \square$ & $600 \square$ & $700 \square$ \\
\hline PP0 & 257 & 322 & -16.9 & & 0 & 0 & 0 \\
PP2 & 258 & 360 & -7.80 & & 27.6 & 13.3 & 1.63 \\
PP5 & 261 & 349 & -7.34 & & 25.4 & 12.9 & 2.8 \\
PP7 & 257 & 330 & -8.34 & & 18.5 & 11.1 & 2.13 \\
\hline
\end{tabular}

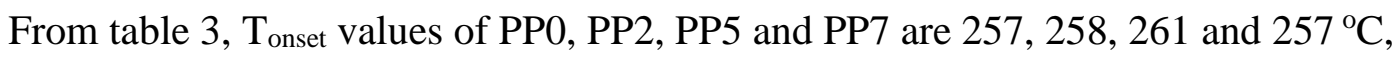
respectively.

DTG curves of PP0, PP2, PP5 and PP7 are shown in figure 4, the relevant data are listed in table 3. The maximum mass loss rate of neat PP is $16.9 \% / \mathrm{min}$ and $\mathrm{T}_{\max }$ is $322^{\circ} \mathrm{C}$. The maximum mass loss rates of PP2, PP5 and PP7 are 7.80, 7.34 and $8.34 \% / \mathrm{min}$, respectively. The maximum mass loss rate of PP5 is lower than others. $\mathrm{T}_{\max }$ values of PP2, PP5 and PP7 are 360,349 and $330^{\circ} \mathrm{C}$, all higher than that of PP0. This indicates that addition of IFR can effectively protect PP from combustion and postpone appearance of maximum mass loss rate. 


\section{5th International Conference On}

Modern Approaches in SCIENCE,

TECHNOLOGY \& ENGINEERING

\section{9 - 31 August, 2019}

Germany, Berlin
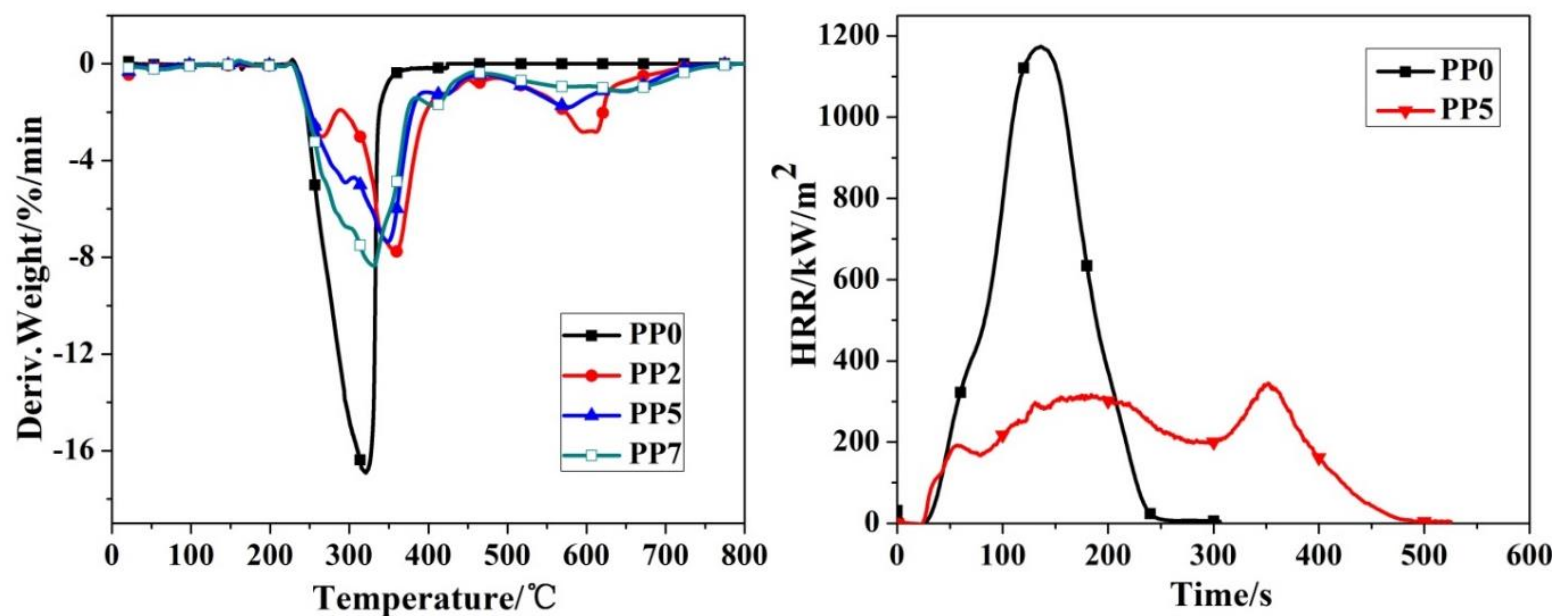

Fig.4 DTG curves of PP0, PP2, PP5 and PP7 Fig.5 HRR curves of PP0 and PP5

\subsection{Cone calorimeter test}

HRR curves of PP0 and PP5 are shown in figure 5.

From figure 5, the curve of PP0 has a single peak and reaches peak heat release rate (pHRR) quickly after ignition, the value of pHRR is $1172 \mathrm{~kW} / \mathrm{m}^{2}$. However, when $30 \mathrm{wt} \%$ IFR is added, there are two peaks in PP5's HRR curve. This is possibly because:

(1) the first peak: APP decomposes to generate polyphosphoric acid which can catalyze esterification and crosslinking reactions between APP and MTHEIC. The generated esterification products can act as protective shield to prevent heat and mass transfer between gas and condense phase to protect under matrix from decomposition.

(2) the second peak: esterification products further decomposes to generate char layer which functions as new intumescent shield to restrain decomposition of PP composites.

The pHRR value of PP5 is $344 \mathrm{~kW} / \mathrm{m}^{2}$, decreasing by $70.6 \%$ compared to that of PP0. The total heat release (THR) values of PP0 and PP5 are 123 and $96 \mathrm{MJ} / \mathrm{m}^{2}$. THR value of PP5 decreases by $22.0 \%$ compared to that of PP0. This indicates addition of IFR can also reduce THR. The time to ignition (TTI) of PP0 is $250 \mathrm{~s}$, TTI of PP5 is 500s, twice as long as that of PPO. 


\section{5th International Conference On}

Modern Approaches in SCIENCE, TECHNOLOGY \& ENGINEERING

\section{9 - 31 August, 2019 \\ Germany, Berlin}
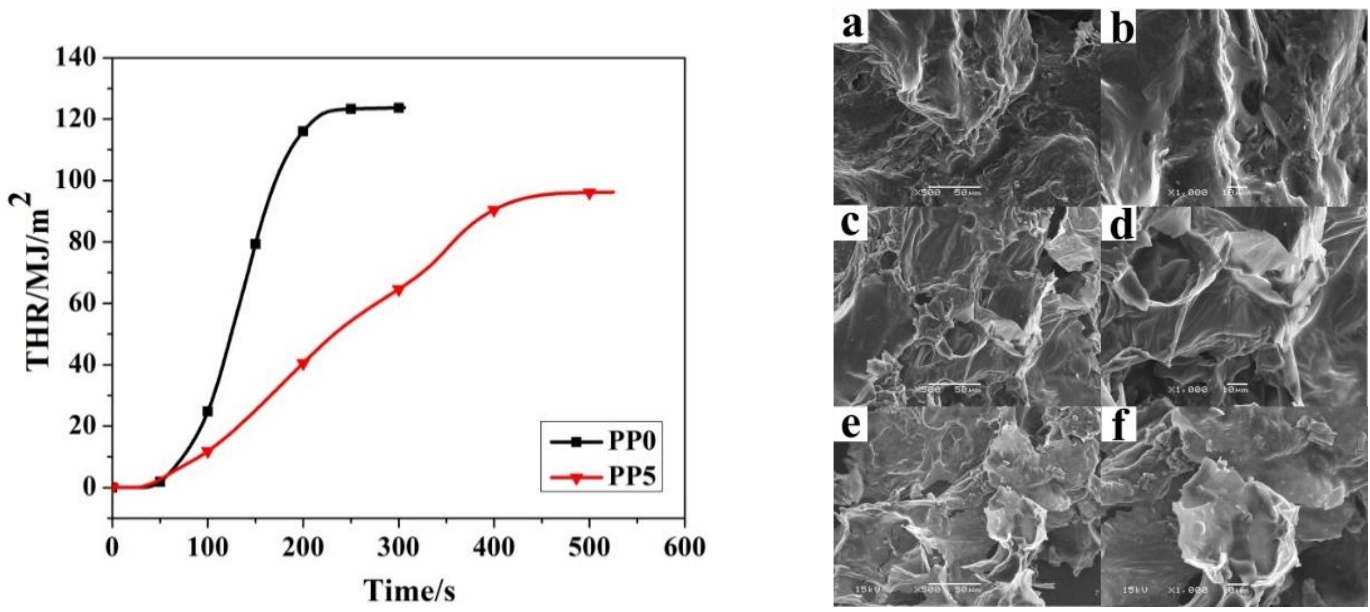

Fig.6 THR curves of PP0 and PP5

Fig.7. SEM images of char for PP2, PP5 and PP7 a. PP $2 \times 500$; b. PP $2 \times 1000$; c. PP5 $\times 500$; d. PP5 $\times 1000$; e. $\mathrm{PP} 7 \times 500$; f. $\mathrm{PP} 7 \times 1000$.

\subsection{Analysis of char morphology}

SEM images of PP2, PP5 and PP7 are shown in figure 7. From figure 7.a and 7.b, the char layer of PP2 looks more like melt products. This is because PP2 can't form a compact and continuous char layer due to lacking of charring agent to generate the carbon skeleton. From figure 7.c and 7.d, the char layer of PP5 is compact and continuous. Many drapes can be found in the surface of char layer, indicating the char layer is very fluffy. Above all, the char layer of PP5 is better in restraining heat and heat transfer between the gas and condense phase and should present higher flame retardancy. From figure 7.e and 7.f, the char layer of PP7 is too compact with few of drapes on the surface. This is because PP7 is lacking of foaming agent to blow the char layer fluffy.

\subsection{Mechanical properties}

The mechanical properties of flame retardant composites are listed in table 4, including tensile strength and flexural strength.

Table 4 Mechanical properties of PP/IFR composites

\begin{tabular}{ccc}
\hline Samples & Tensile strength $(\mathrm{MPa})$ & Flexural strength $(\mathrm{MPa})$ \\
\hline PP0 & 37.49 & 42.08 \\
PP1 & 24.34 & 33.39 \\
PP2 & 26.93 & 33.88 \\
PP5 & 25.99 & 33.65 \\
PP7 & 25.33 & 33.24 \\
\hline
\end{tabular}


It can be seen that the addition of APP into PP (PP1) decreases tensile strength $35.1 \%$ and flexural strength $20.7 \%$. When APP/MTHEIC is added together into PP, the reduce of tensile strength and flexural strength (PP2) are $28.1 \%$ and $19.5 \%$, respectively. For different mass ratio of APP/MTHEIC, the reduce of tensile strength and flexural strength are similar. This indicates when $30 \mathrm{wt} \%$ IFR is added, whatever their components, the effects on mechanical properties are similar.

\subsection{Water Resistance}

In order to investigate water resistance of PP/IFR composites, PP/APP/THEIC and PP/ APP/MTHEIC composites (with mass ratio 2:1 and IFR 30wt\%) were soaked in water at $70{ }^{\circ} \mathrm{C}$ for different time and their flame retardancy properties were tested, including LOI and UL-94 tests. The results were listed in table 5 .

Table 5 The water resistance of PP/APP/THEIC 和PP/APP/MTHEIC composites

\begin{tabular}{ccccccc}
\hline \multirow{2}{*}{$\begin{array}{c}\text { Soaking time } \\
\text { hrs }\end{array}$} & \multicolumn{2}{c}{ PP/APP/THEIC } & & \multicolumn{2}{c}{ PP/APP/MTHEIC } \\
\cline { 2 - 3 } 12 & LOI $\%$ & UL-94 & & LOI \% & UL-94 \\
24 & 34.8 & V-0 & & 35.0 & V-0 \\
48 & $/$ & V-2 & & 33.8 & V-0 \\
96 & $/$ & N.R & & 32.0 & V-0 \\
120 & $/$ & $/$ & & 31.3 & V-0 \\
144 & $/$ & $/$ & & 30.9 & V-0 \\
168 & $/$ & $/$ & & 29.3 & V-1 \\
\hline
\end{tabular}

PP/APP/THEIC composite only obtained a V-2 rating after 24 hrs, with melt dripping during combustion process. After $48 \mathrm{hrs}$, no rating could be obtained. However, PP/APP/MTHEIC composite could still obtain V-0 rating after $120 \mathrm{hrs}$ soaking time with LOI value $30.9 \%$, it decreases to V-1 after 144 hrs soaking time with LOI value $29.3 \%$, and it has no rating after 168 hrs. The results indicated PP/APP/MTHEIC composite has good water resistance than PP/APP/THEIC, this is because MTHEIC is condensed by THEIC and MAH, MTHEIC is a copolymerized molecular structure, as shown in scheme 1, the molecular weight is greatly increased, its compatibility with PP is increased, and the hydrophilic groups in THEIC are converted to hydrophobic esterification groups in MTHEIC. Similar results were obtained when THEIC are esterified with terephthalic acid, in which PP/APP/TBCA composites ${ }^{18}$ (mass ratio APP/TBCA 2:1 and IFR $30 \mathrm{wt} \%$ ) had better water resistance than PP/APP/THEIC composite. PP/APP/TBCA composite could obtain V-0 rating after $96 \mathrm{hrs}$ soaking time with LOI value $29.7 \%$, and it has no rating after $120 \mathrm{hrs}$. This indicates the water resistance of MTHEIC is better than TBCA. Up till now, in all THEIC-based charring agents, we found MTHEIC has the best water resistance. Of course, we wish to synthesize the THEIC-based charring agent which can pass V-0 rating after soaking in hot water for $168 \mathrm{hrs}$. 


\section{5th International Conference On}

Modern Approaches in SCIENCE,

\section{Conclusion}

Another THEIC-based charring agent MTHEIC was successfully synthesized, its chemical structure was characterized by FTIR spectra, ${ }^{1} \mathrm{H}-\mathrm{NMR}$ spectra and elemental analysis. Results of UL-94 and LOI showed that $30 \mathrm{wt} \%$ loading of IFR and APP/MTHEIC 2:1 could increase LOI value to $35.2 \%$ and pass UL-94 V-0 rating. TGA curves suggested that addition of IFRs could increase char residue and showed high thermal stability.

When APP/MTHEIC is added together into PP, the reduce of tensile strength and flexural strength (PP2) are $28.1 \%$ and $19.5 \%$. PP/APP/MTHEIC composite could obtain V-0 rating after 120 hrs soaking time with LOI value $30.9 \%$, it decreases to V-1 after 144 hrs soaking time with LOI value $29.3 \%$, and it has no rating after $168 \mathrm{hrs}$. Though the water resistance of MTHEIC is better than TBCA, seeking a THEIC-based charring agent which can pass V-0 rating after soaking in hot water for $168 \mathrm{hrs}$ is in progress.

\section{References}




\section{9 - 31 August, 2019 Germany, Berlin}

1. Demir H., Arkis E., Balkose D., Ulku S. Synergistic effect of natural zeolites on flame retardant additives. Polym. Degrad. Stab., 2005,89,478-483.

2. Bourbigot S., Le Bras M., Delobel R., Decressain R., Amourex JP. Synergistic effect of zeolite in an intumescent process study of the carbonaceous structure using solid-state NMR. J. Chem. Soc. Faraday Trans., 1996,92,149-158.

3. Camino G., Costa L., Trossarelli L. Study of the mechanism of intumescence in fire retardant polymers: Part II-Mechanism of action in polypropylene-ammonium polyphosphate-pentaerythritol mixtures. Polym. Degrad. Stab., 1984,7,25-31.

4. Q. Tang, B. Wang, G. Wang, Y. Shi, X. Qian, B. Yu, L. Song, Y. Hu. Preparation of microcapsulated ammonium polyphosphate, pentaerythritol with glycidyl methacrylate, butyl methacrylate and their synergistic flame-retardancy for ethylene vinyl acetate copolymer. Polym. Adv. Technol. 2014,25,73-82.

5. Wang Y., Xu M.J., Li B. Synthesis of N-methyl triazine-ethylenediamine copolymer charring foaming agent and its enhancement on flame retardancy and water resistance for polypropylene composites. Polym. Degrad. Stab., 2016,131,20-29.

6. Feng C.M., Liang M.Y., Jiang J.L., Huang J.G. Liu H.B. Synergistic effect of a novel triazine charring agent and ammonium polyphosphate on the flame retardant properties of halogen-free flame retardant polypropylene composites. Thermochim. Acta., 2016,627629,83-90.

7. Su X.Q., Yi Y.W., Tao J., Qi H.Q., Li D.Y. Synergistic effect between a novel triazine charring agent and ammonium polyphosphate on flame retardancy and thermal behavior of polypropylene. Polym. Degrad. Stab., 2014,105,12-20.

8. Feng C.M., Liang M.Y., Jiang J.L., Liu H.B. Huang J.G. Synergistic effect of ammonium polyphosphate and triazine-based charring agent on the flame retardancy and combustion behavior of ethylene-vinyl acetate copolymer. J. Anal. Appl. Pyrolysis, 2016,119,259-269.

9. Li J., Ke C.H., Xu L., Wang Y.Z. Synergistic effect between a hyperbranched charring agent and ammonium polyphosphate on the intumescent flame retardance of acrylonitrilebutadiene-styrene polymer. Polym. Degrad. Stab., 2012,97,1107-1113.

10. B. Li and M.J. Xu. Effect of a novel charring foaming agent on flame retardancy and thermal degradation of intumescent flame retardant polypropylene. Polym. Degrad. Stab. 2006,91,1380-1386.

11. C.H. Ke, J. Li, K.Y. Fang, Q.L. Zhu, J. Zhu, Q. Yan, Y.Z. Wang. Synergistic effect between a novel hyperbranched charring agent and ammonium polyphosphate on the flame retardant and anti-dripping properties of polylactide. Polym. Degrad. Stab. 2010,95,763770.

12. X.P. Hu, Y.L. Li and Y.Z. Wang. Synergistic effect of the charring agent on the thermal and flame retardant properties of polyethylene. Macromol. Mater. Eng. 2004,289,208-212.

13. S.B. Nie, Y. Hu, L. Song, Q.L. He, D.D. Yang and H. Chen. Synergistic effect between a char forming agent (CFA) and microencapsulated ammonium polyphosphate on the thermal and flame retardant properties of polypropylene. Polymer for Advanced 


\section{5th International Conference On}

Modern Approaches in SCIENCE,

TECHNOLOGY \& ENGINEERING

\section{9 - 31 August, 2019 \\ Germany, Berlin}

Technologies, 2008,19,1077-1083.

14. Wen P.Y., Wang X.F., Wang B.B., Yuan B.H., Zhou K.Q., Song L., Hu Y. Richard K.K. One-pot synthesis of a novel s-triazine-based hyperbranched charring foaming agent and its enhancement on flame retardancy and water resistance of polypropylene. Polym. Degrad. Stab., 2014,110,165-174.

15. N. Chang, C.H. Zhang, F.E. Zheng, Y.L. Huang, J.Y. Zhu, Q. Zhou, X. Zhou, S. J. Ji. Migration of toluene through different plastic laminated films into food simulants. Food Control, 59(2016)164-171.

16. Regulation $1935 / 2004 / \mathrm{EC}$ of the European parliament and of the council of 27 October 2004. Official journal of the European Union C Series, 338,4-17.

17. S.S. Yuan, W.Y. Chen and G.S. Liu. Synergistic effect of THEIC-based charring agent on flame retardant properties of polylactide. J. Applied Polym. Sci., 132(2015)65-69.

18. W.Y. Chen and G.S. Liu. Flame-retardancy properties of tris(2-hydroxyethyl) isocyanurate based charring agents on polypropylene. J. Appl. Polym. Sci., 132(2015)5126-5132.

19. S.S. Yuan, W.Y. Chen and G.S. Liu. Effects of two kinds of THEIC-based charring agent on flame retardant properties of polylactide. J. Appl. Polym. Sci., 132(2015)7495-7502.

20. Z.W. Jiang and G.S. Liu. Microencapsulation of ammonium polyphosphate with melamine-formaldehyde tris(2-hydroxyethyl) isocyanurate resin and its flame retardancy in polypropylene. $R S C A d v$., 5(2015) 88445-88455.

21. S. Gao, X. Zhao and G.S. Liu. Synthesis of tris(2-hydroxyethyl) isocyanurate homopolymer and its application in intumescent flame retarded polypropylene. J. Appl. Polym. Sci., 2017, 134(13): 44663.

22. S. Gao, X. Zhao and G.S. Liu. Synthesis of an integrated intumescent flame retardant and its flame retardancy properties for polypropylene. Polym. Degrad. Stab., 2016. 138: 106114.

23. X. Zhao, S. Gao, and G.S. Liu. A THEIC-based polyphosphate melamine intumescent flame retardant and its flame retardancy properties for polylactide. J. Anal. Appl. Pyrolysis, 2016,122,24-34. 